\title{
Biomimetic Coating of Modified Titanium Surfaces with Hydroxyapatite Using Simulated Body Fluid
}

\author{
Mohsin Nazir,, Ong Pei Ting, ${ }^{2}$ Tan See Yee, ${ }^{2}$ Saravanan Pushparajan, \\ Dasan Swaminathan, ${ }^{1}$ and Muralithran G. Kutty ${ }^{1}$ \\ ${ }^{1}$ Department of Restorative Dentistry, Faculty of Dentistry, University of Malaya, 50603 Kuala Lumpur, Malaysia \\ ${ }^{2}$ Faculty of Dentistry, University of Malaya, 50603 Kuala Lumpur, Malaysia
}

Correspondence should be addressed to Mohsin Nazir; mohsin-101@hotmail.com

Received 18 May 2015; Revised 21 August 2015; Accepted 8 September 2015

Academic Editor: Michele Iafisco

Copyright (C) 2015 Mohsin Nazir et al. This is an open access article distributed under the Creative Commons Attribution License, which permits unrestricted use, distribution, and reproduction in any medium, provided the original work is properly cited.

This study investigated the viability of coating commercially pure titanium (CPTi) surfaces, modified via sandblasting and acid etching, with hydroxyapatite (HA)/tricalcium phosphate coatings using a simulated body fluid (SBF) solution. The samples were immersed in SBF from 3 to 7 days. The morphology and the chemistry of the HA/tricalcium phosphate coating were then analysed. Prior to immersion in SBF, the samples were sandblasted and acid etched to mimic the morphology and roughness of commercially available dental implants. The SBF aided in the formation of crystalline HA/tricalcium phosphate coatings on all the samples. The coatings were uniform and had roughness values higher than the underlying substrate. The highest roughness values for the coatings on the surfaces were obtained at 7 days of immersion in SBF with average $S_{a}$ values of $2.9 \pm 0.2 \mu \mathrm{m}$. The presence of HA/tricalcium phosphate on the surfaces was confirmed by the Scanning Electron Microscope (SEM), Energy Dispersive Spectrometer (EDS), the X-Ray Diffraction (XRD), and the Fourier Transform Infrared Spectrometer (FTIR) analysis. This study shows that it is possible to obtain an adequate and uniform hydroxyapatite coating on pure titanium substrates in a shorter period of time with characteristics that favour the ultimate goal of implants therapy, that is, osseointegration.

\section{Introduction}

There has been extensive research on titanium surface modifications in order to improve the time and quality of implant therapy. It has been found that the surface roughness of implants directly influences the speed of healing and the quality of the bone-implant interface [1]. An ideal surface roughness of $1-2 \mu \mathrm{m}$ is deemed optimal if desirable results are to be accomplished [2]. In recent times, the commonest technique used to achieve surface roughness in dental implants is a combination of grit-blasting and acid etching. This combination produces both microroughness and waviness which significantly increase early endosseous integration, peri-implant bone healing, and the stability of the implant [3].

After attaining a prescribed value for roughness and morphology, an obstacle henceforth is to create titanium surfaces that are biomimetic. The shifting paradigm of implant surface technology makes researchers employ nature as their guide.
The human bone inherently embodies hydroxyapatite (HA) [4]. A significant mineral portion of the bone is composed of these nanometre sized calcium phosphate crystals that measure up to about 5-20 nm in width and $60 \mathrm{~nm}$ in length. A cycle of osteoclastic and osteoblastic activity ensures that a certain haemostatic level of HA is maintained at all times in living bone [5]. HA is a bioactive and biocompatible material and has been used rigorously in research and clinical settings in various shapes and forms [6]. HA could influence protein interactions and consequently lead to favourable healing and greater osteoblast adhesion, proliferation, and differentiation $[7,8]$.

There is extensive literature that deals with the various procedures of acquiring HA coating on different surfaces. Amongst these methods, the wet chemical deposition, thermal plasma spraying, pulse laser deposition, the sol-gel, electrodeposition, and biomimetic deposition are the ones that have been reported [9]. One of the easiest methods amid these 
techniques that satisfies the various needs of implant therapy is the biomimetic deposition method in which a simulated body fluid (SBF) solution is made in accordance with the inorganic ingredients of the human blood plasma [10-12].

The fact that SBF creates apatite crystals that resemble human bone on titanium and other surfaces is testified by various literatures [12-15]. The ability of forming this apatite layer often determines the bonding ability of an implant material to adjacent living bone [16]. This bioactive deposition can stimulate bone apposition and the healing process. Hence, early osseointegration of titanium implants can be established [17-21]. When SBF is used to coat titanium surfaces, a wide range of therapeutic or biomimetic agents can be incorporated into the layer that forms on the titanium surface. This opens new doors into medicinally or biomimetically enhancing the implant surface ensuring a steady and controlled release of the surface constituents [4, 22, 23].

There have been various studies to date that use the $\mathrm{HA} /$ calcium phosphate to coat titanium surfaces. The authors of this paper are not aware of any research that uses modified sandblasted and acid etched titanium surfaces with the TasSBF solution according to the work performed by Jalota et al. [24]. Therefore, the aim of this study is to investigate the viability of coating modified CPTi surfaces with HA/calcium phosphate coating using a Tas-SBF solution.

\section{Materials and Methods}

2.1. Samples. For this study, 4 commercially pure grade 2 titanium (CPTi) discs from E-Steel Sdn. Bhd. were used. The discs were square in shape and measured $10 \mathrm{~mm} \times 10 \mathrm{~mm}$.

\subsection{Surface Standardization and Modification. Silicon car-} bide paper with 400 grit was used for standardizing and hence gritting the titanium substrates by using a twin variable speed grinding and polishing machine for two minutes at $300 \mathrm{rpm}$. The gritted titanium substrates were then sandblasted to increase their surface roughness by using a sandblasting machine (Model number SB-8060-KP Techno Finishing Sdn. Bhd.). Grade A brown alumina of mesh 120 and an average abrasive grain size of $125 \mu \mathrm{m}$ was blasted at a distance of $5 \mathrm{~cm}$ perpendicular to the sample surface through an air gun for approximately 3 seconds, at a pressure of 50 psi. The samples were then rinsed in ethanol and distilled water to remove the sandblasted residua and contaminants from the samples surface, followed by air-blasting until they were dried.

An Alicona Infinite Focus Optical 3D Measurement Device G4f was used to capture three-dimensional stereoimages of the implant surface at seven areas on each of the titanium surfaces. The average height parameter $\left(S_{a}\right)$ of the surfaces studied was measured up to millimetre scale using the IFM 2.1.5 software. For every surface, the area of measurement was within the limit of $40 \mu \mathrm{m} \times 40 \mu \mathrm{m}$ in dimension. Seven measurements were taken and an average value and standard deviation of implant surface roughness were calculated henceforth.

The sandblasted CPTi samples were then acid etched by using a mixture of $37 \%$ hydrochloric acid $(\mathrm{HCl})$ and $98 \%$ sulphuric acid $\left(\mathrm{H}_{2} \mathrm{SO}_{4}\right)$ with a volumetric ratio of $1: 3$, respectively. $5 \mathrm{~mL} \mathrm{HCl}$ and $15 \mathrm{~mL} \mathrm{H}_{2} \mathrm{SO}_{4}$ were diluted in $100 \mathrm{~mL}$ distilled water. This dual acid solution was kept in a water bath of $80^{\circ} \mathrm{C}$ for 30 minutes and it was ensured that the surface to be etched was facing the acidic solution. The samples were then taken out and cleaned with ethanol and distilled water, followed by air-blasting to dry the titanium surfaces. These acid etched CPTi samples were observed again under the Alicona machine and the surface roughness was measured.

2.3. Addition of the Hydroxyl Group. After acid etching, the samples were treated with sodium hydroxide $(\mathrm{NaOH})$ so that the surfaces could be activated with hydroxyl groups from the alkaline solution. The CPTi discs were immersed inside a $50 \mathrm{~mL} 5 \mathrm{M} \mathrm{NaOH}$ solution for 24 hours at $60^{\circ} \mathrm{C}$ in an oven, followed by rinsing in distilled water and drying at $40^{\circ} \mathrm{C}$ [24].

2.4. SBF Coating. Subsequently, a TRIS-buffered $1.5 \mathrm{x}$ TasSBF solution was prepared based on the work by Jalota et al. [24]. A magnetic stirrer plate (Model name: Favorit) was used in order to mix the solution well for 2 hours at a speed of $700 \mathrm{rpm}$. All four titanium surfaces were immersed in the Tas-SBF solution and incubated at a temperature of $37^{\circ} \mathrm{C}$ for a total of 7 days. In the initial 3 days, the Tas-SBF solution was changed for all samples daily at 24-hour intervals. From the third day onwards, the Tas-SBF solution was replenished after every 48 hours till the seventh day.

2.5. Surface Analysis. Lastly, the Alicona (Infinite Focus Optical 3D Measurement Device G4f Metrology) was used to evaluate the surface roughness. The Scanning Electron Microscope (SEM) (Low Vacuum Operating Mode, Model number FEI Quanta 250F) was kept at $10 \mathrm{kV}$, with a Working Distance (WD) of $10 \mathrm{~mm}$ and magnifications of 2000x, $10,000 x$, and $20,000 x$, to analyse the surface morphology and thickness. The X-Ray Diffraction (XRD) (Bruker X-Ray Powder Defractometer) and the Fourier Transform Infrared Spectrometer (FTIR Spectrometer) (Model number Nicolet 6700 FTIR, Thermo Scientific.) were used to check the $\mathrm{HA} /$ tricalcium phosphate compound presence and elemental composition of the Tas-SBF coated samples on the 3rd, 4th, 5 th, 6 th, and 7 th day, respectively.

\section{Results and Discussion}

3.1. Results. Analysis of the surface roughness profiles of the samples, using $S_{a}$ values, showed that for sandblasted and acid etched samples CPTi displayed a higher $S_{a}$ than an unstandardized CPTi surface. Within the SBF coated samples, there was a general increase in $S_{a}$ in all surfaces involved. The SBF coatings on the fifth, sixth, and seventh day showed higher $S_{a}$ values as compared to the third and the fourth day. Figure 1 shows a graphical representation of the $S_{a}$ values obtained. There was an increase in $S_{a}$ value for commercially pure titanium from approximately $1.6 \pm 0.1 \mu \mathrm{m}$ at the sandblasting stage to about $2.9 \pm 0.2 \mu \mathrm{m}$ on seventh day of immersion in SBF solution with a decline in $S_{a}$ value on sixth day.

Figure 2 shows the FTIR spectrum peaks. Analysis with the FTIR spectrum for the SBF coatings on different days of 


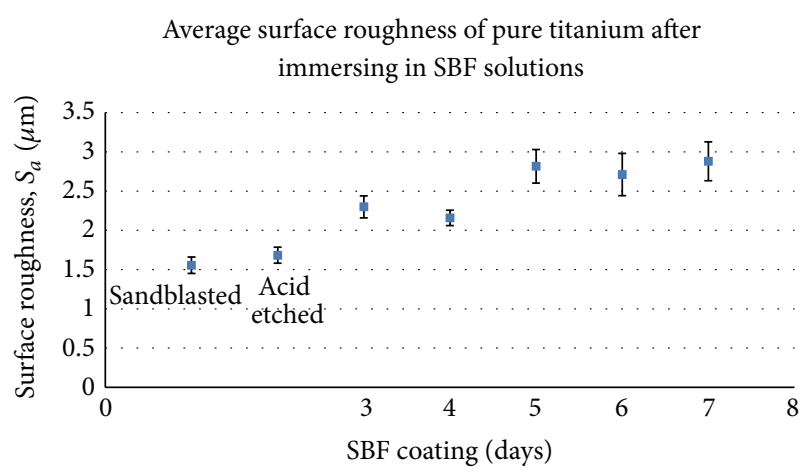

FIgURE 1: Graph showing $S_{a}$ values of the CPTi samples at various stages and times during the experiment.

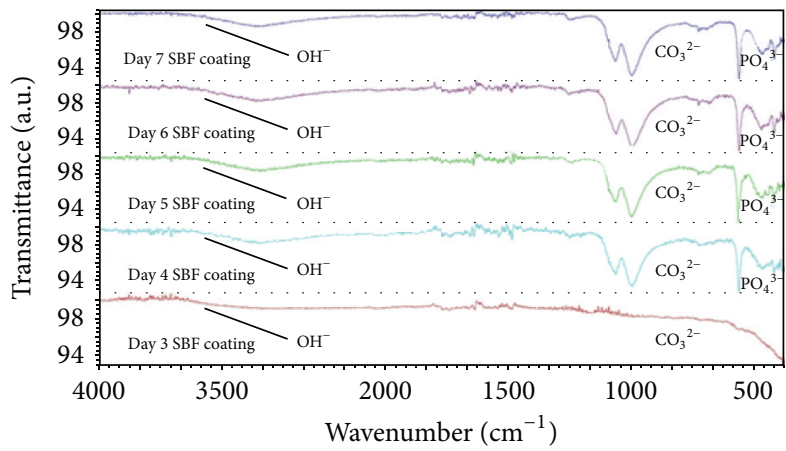

FIGURE 2: Showing the FTIR spectrum peaks for CPTi surfaces. Wavenumber $\left(\mathrm{cm}^{-1}\right)$.

immersion of CPTi surfaces showed a gradual elevation in the peak intensity linked with an increase in the number of SBF immersion days. The absorption bands at $1400-1550 \mathrm{~cm}^{-1}$ are the peak of $\mathrm{CO}_{3}{ }^{2-}$ group and $560-600 \mathrm{~cm}^{-1}$ and $1030-$ $1090 \mathrm{~cm}^{-1}$ are the characteristic peaks of the $\mathrm{PO}_{4}{ }^{3-}$ group, whereas bands around $3500 \mathrm{~cm}^{-1}$ show the presence of $\mathrm{OH}^{-}$ groups. With the results of the FTIR spectrum, it was not possible to deduce that HA/tricalcium phosphate was present on the sample surfaces. Hence, additional analytical evaluation was required.

The EDS results showed that CPTi gives the typical $\mathrm{Ti}$ peak with the presence of $\mathrm{Ca}, \mathrm{P}$, and $\mathrm{O}$ from the $\mathrm{HA}$ / tricalcium phosphate coating. Figure 3 shows the EDS analysis of CPTi surfaces coated with HA/tricalcium phosphate. All the elements shown are the result of the formation of HA/tricalcium phosphate from the simulated body fluid solution. The $\mathrm{Ca} / \mathrm{P}$ ratio was $1: 2$, respectively, at the end of the seventh day of Tas-SBF immersion. There were no impurities detected from the sandblasting process or the coating methodology ensuring success of the HA/tricalcium phosphate coating.

The X-Ray Diffraction (XRD) patterns in this study can be viewed in Figure 4. The highest peaks seen in all the samples belonged to substrate metals in the Tas-SBF. XRD beams can penetrate the thin coatings of hydroxyapatite and are diffracted from the underlying metals. For the samples that were immersed in Tas-SBF for three days, the presence
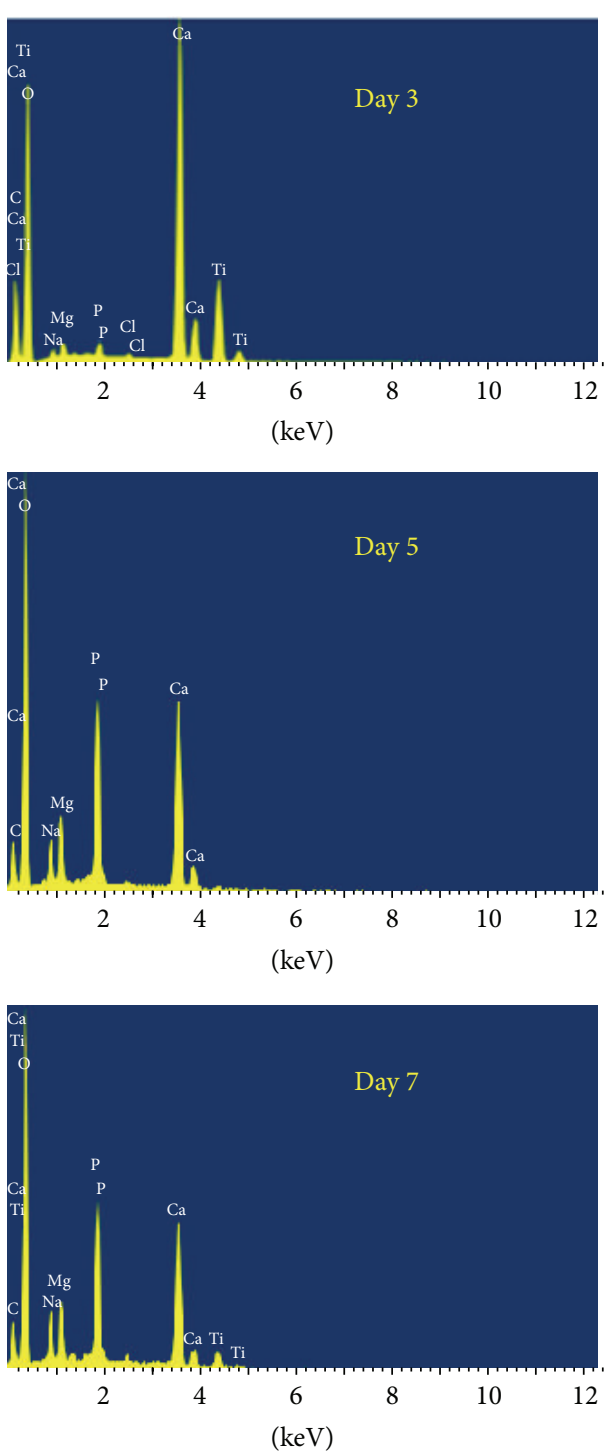

Full scale 1344 cfs cursor: 0.000

FIGURE 3: Showing the EDS of CPTi samples coated with $\mathrm{HA} /$ tricalcium phosphate.

of $\mathrm{HA} /$ tricalcium phosphate is just visible with a small peak at $2 \theta$ angle of $32^{\circ}$. As the coating time was increased, the intensity of the HA/tricalcium phosphate peaks also increased gradually indicating more deposition of the HA/tricalcium phosphate crystals. The only anomaly was seen on the fourth day of the Tas-SBF coated titanium alloy samples where $\mathrm{HA} /$ tricalcium phosphate peaks are barely visible. This could be attributed to HA/tricalcium phosphate coating discrepancies or mishandling of the sample.

When the SEM was used to analyse pre- and post-HA coated samples, the acid etched surfaces showed multiple pits and craters. CPTi bore a uniform and well-defined porous surface. In addition to small acid induced indentations, the surfaces displayed large concavities that were induced by the sandblasting process that preceded acid etching. Figure 5 




FIGURE 4: Showing the XRD analysis of the surface on various days of the experiment.


FIGURE 5: Showing the appearance of the acid etched CPTi samples under the SEM at 2000x and 5000x magnification.

shows the SEM micrographs of the acid etched surfaces of CPTi.

Under the SEM, the Tas-SBF coated surfaces possessed a crystalline coating indicated by an intricate crystal assembly that resembled a "flower-like" structure. This is typical of the formation of $\mathrm{HA}$ and calcium phosphate crystals that deposit from the Tas-SBF solution. For the CPTi, the crystal size of the coating was bigger on the seventh day of immersion into Tas-SBF as compared to the third, fourth, fifth, and sixth day. Figure 6 shows the SEM micrographs of the HA coating on the third, fourth, fifth, sixth, and seventh day at different magnification.

The thickness of the coated surfaces was also measured for the samples at various days of immersion in the Tas-SBF solution. Figure 7 shows the thickness of the surface coating on the fifth day which was $14.4 \pm 0.2 \mu \mathrm{m}$.

3.2. Discussion. The surface roughness of a dental implant has been shown to have an appreciable effect on the surrounding bone of the implant [25]. It is an important factor that could influence the way osteoblasts attach onto titanium surfaces. Studies indicate that average $S_{a}$ values of about 1 and $2 \mu \mathrm{m}$ optimize osseointegration at the bone-implant interface $[26,27]$. So taking this into consideration, sandblasting and acid etching were performed on the surfaces to introduce surface roughness as it increases the surface area for bone contact and hence induces successful implant treatment [28]. It was possible to attain a surface similar to the acid etched surface of 


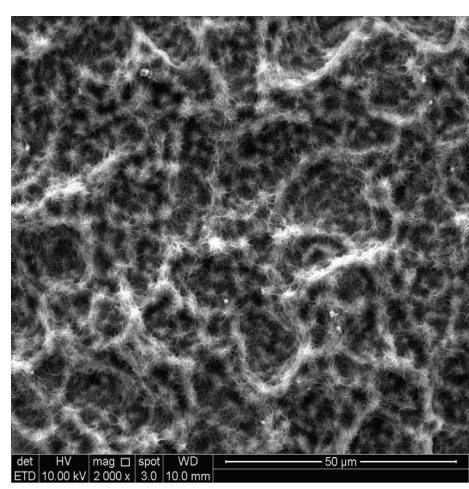

Mag.: 2000x

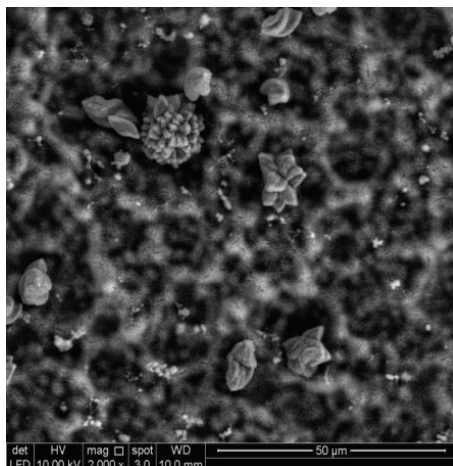

Mag.: 2000x



Mag.: 2000x

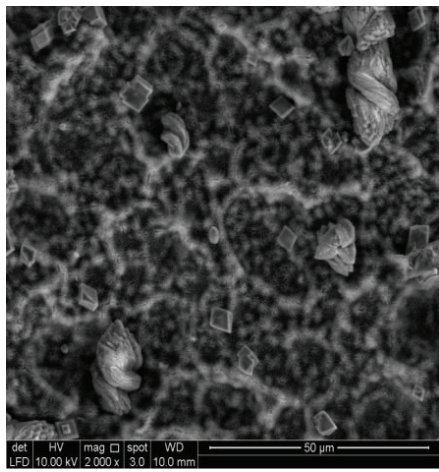

Mag.: 2000x

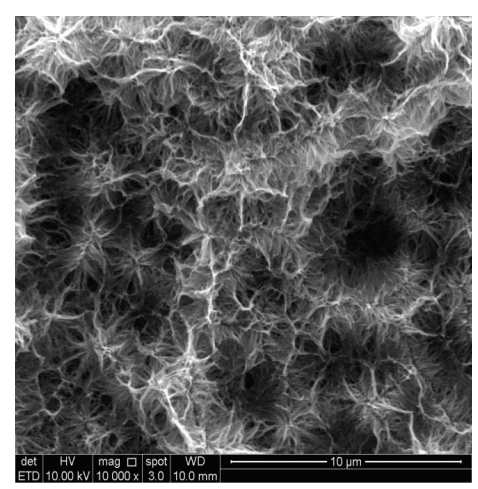

Mag.: 10,000x

(a)



Mag.: 10,000x

(b)

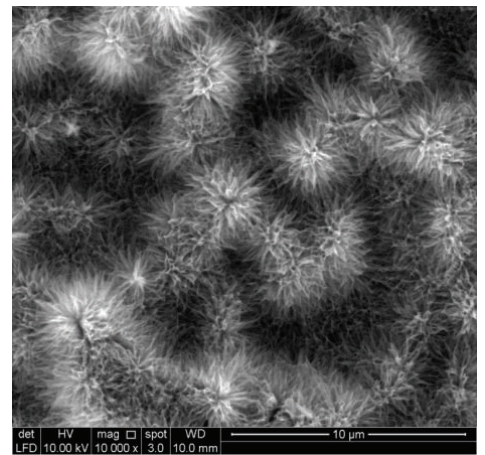

Mag.: 10,000x

(c)

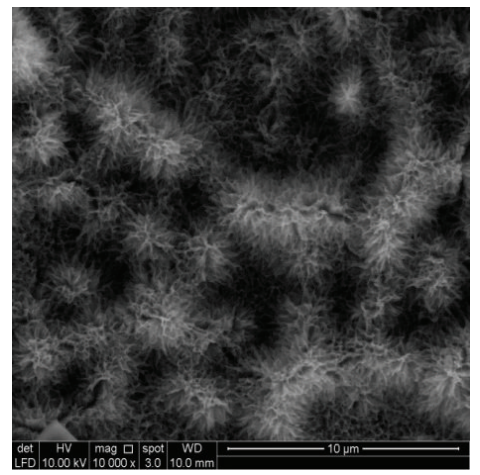

Mag.: 10,000x

(d)

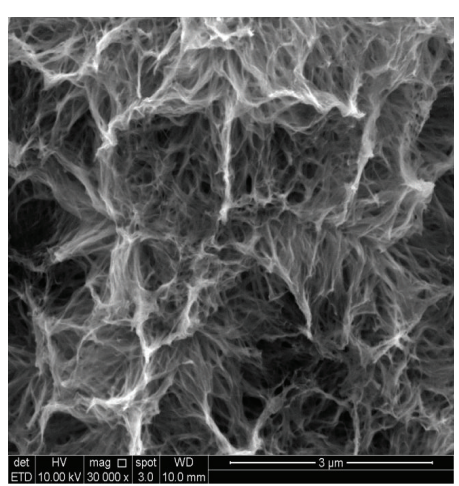

Mag.: 30,000x

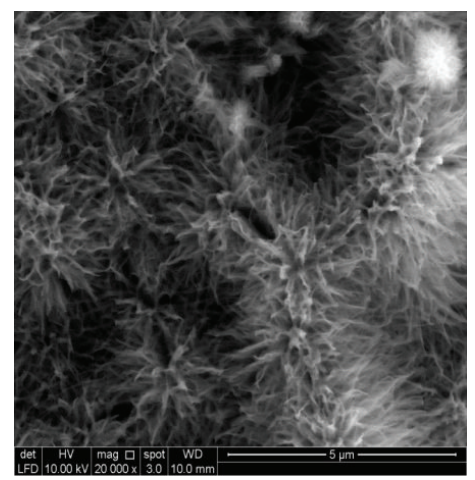

Mag.: 20,000x

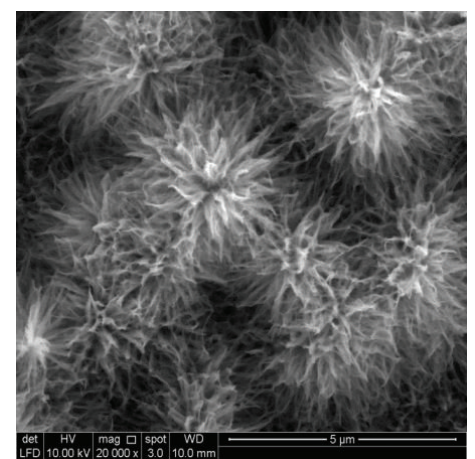

Mag.: 20,000x

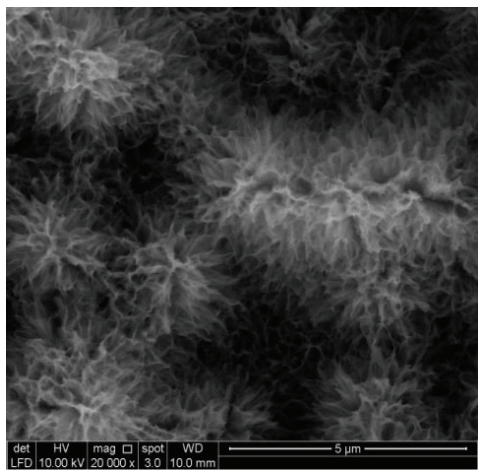

Mag.: 20,000x

FIgure 6: Continued. 


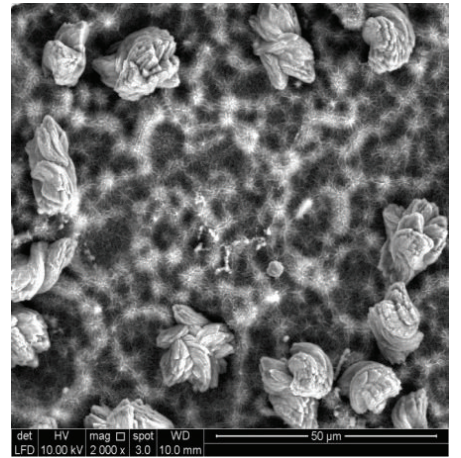

Mag.: 2000x

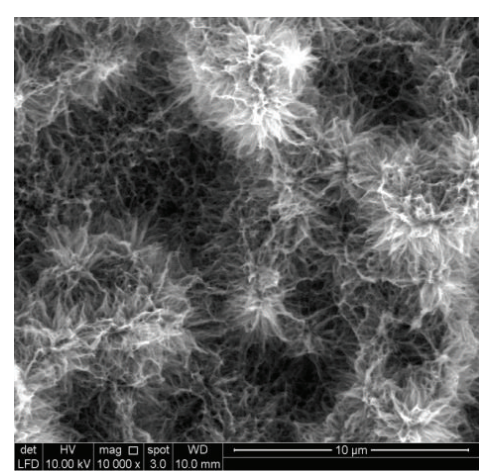

Mag.: 10,000x

(e)

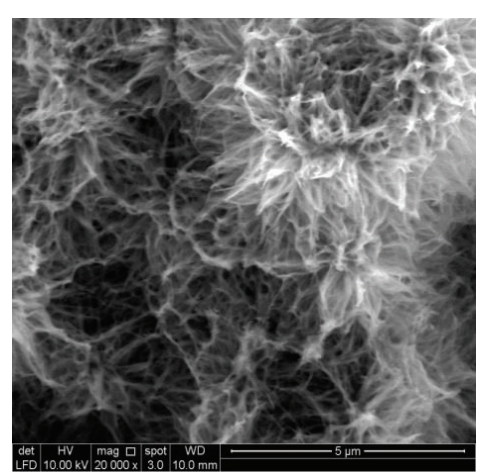

Mag.: 20,000x

FIGURE 6: (a)-(e) Showing SEM micrographs of the HA coating on CPTi surfaces on the third, fourth, fifth, sixth, and seventh day, respectively, at different magnifications.

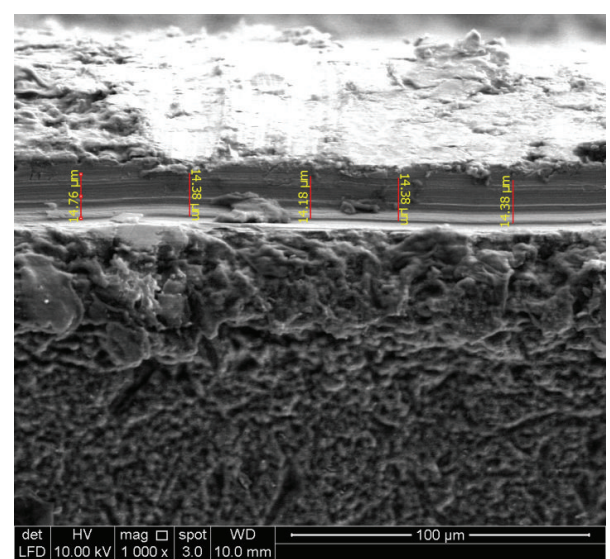

Figure 7: Showing $14.4 \pm 0.2 \mu \mathrm{m}$ surface layer thickness of the sample on the fifth day of Tas-SBF immersion.

a commercial implant with roughness between 1 and $2 \mu \mathrm{m}$. The process of acid etching was also able to remove the residual impurities from the surface left by the sandblasting process that usually leaves alumina particles embedded in the sample [29]. EDS and XRD analysis of the surfaces did not show a presence of alumina in any sample.

After modifying the surface, latest research suggests the application of various biomimetic coatings that can be beneficial for implant therapy success $[30,31]$. This study employed an HA surface coating on the samples because of its proven osteoconductive properties [32]. The biomimetic approach which exploits the advantageous consequences of using TasSBF solution to coat HA onto titanium surfaces was used. An HA layer on titanium surfaces using Tas-SBF is capable of achieving crystallinity and morphology similar to those of a bone-like apatite [33]. A favourable aspect of this study coincides with the proposition that increased crystallinity of HA coatings appears to slow resorption of HA [34].

The surface roughness of the Tas-SBF coated samples in this study showed a significant increase after the experiment reached its conclusion. This is important to note because consequentially this layer could improve the surface area for cell attachment and proliferation. The FTIR spectrum analysis showed peaks for - $\mathrm{OH}$ bond which was an indication that the surface contained HA. The XRD data showed peaks indicating the presence of crystalline HA phases as well. It can be concluded from the results that it was possible in this study to obtain a bioactive thin and relatively uniform coatings of HA on both pure titanium and titanium alloy surfaces.

Another key parameter is that the duration of immersion into the Tas-SBF solution has an effect on the surface roughness and also the crystal size of the HA/calcium phosphate coating. Generally, biomimetic coating processes are performed for about seven to fourteen days [35]. There are some treatment methods however that temper with the concentration and constituents of Tas-SBF solutions and can considerably reduce the Tas-SBF immersion time to create a favourable HA/calcium phosphate deposition [36, 37]. This study was conversely able to ascertain that it is possible to reduce the time of Tas-SBF immersion while maintaining the standard Tas-SBF solution concentration. This was done by preparing surfaces that had negligible influence on the composition and the morphology of the coating. Furthermore, this research was able to prove that a more uniform and thinner layer of $\mathrm{HA} /$ tricalcium phosphate that was immersed in Tas-SBF for seven days or less may be sufficient for implant surface coating. The biomimetic coating obtained for all the Tas-SBF immersion periods portrayed compositional and structural features that closely resembled human bone.

\section{Conclusion}

This study was successful in investigating that coating HA/tricalcium phosphate on titanium surfaces with the TasSBF solution for 7 days to achieve uniform and thin coatings is a viable option for biofunctionalizing titanium surfaces. Further research needs to be conducted in this sphere of implantology so as to improve implant therapy.

\section{Conflict of Interests}

The authors declare no conflict of interests. 


\section{Acknowledgments}

The authors wish to express appreciation for technical assistance and laboratory support of University of Malaya, Faculty of Dentistry. They would also like to acknowledge the help of all the departments involved and the UMRG Grant RG53813HTM for funding this research.

\section{References}

[1] S. Tetè, F. Mastrangelo, T. Traini et al., "A macro- and nanostructure evaluation of a novel dental implant," Implant Dentistry, vol. 17, no. 3, pp. 309-320, 2008.

[2] M. B. Rosa, T. Albrektsson, C. E. Francischone, H. O. Schwartz Filho, and A. Wennerberg, "The influence of surface treatment on the implant roughness pattern," Journal of Applied Oral Science, vol. 20, no. 5, pp. 550-555, 2012.

[3] A. B. Novaes Jr., S. L. S. de Souza, R. R. M. de Barros, K. K. Y. Pereira, G. Iezzi, and A. Piattelli, "Influence of implant surfaces on osseointegration," Brazilian Dental Journal, vol. 21, no. 6, pp. 471-481, 2010.

[4] S. Liao, B. Li, Z. Ma, H. Wei, C. Chan, and S. Ramakrishna, "Biomimetic electrospun nanofibers for tissue regeneration," Biomedical Materials, vol. 1, no. 3, article R45, 2006.

[5] M. Ferraz, F. Monteiro, and C. Manuel, "Hydroxyapatite nanoparticles: a review of preparation methodologies," Journal of Applied Biomaterials and Biomechanics, vol. 2, pp. 74-80, 2004.

[6] W. Suchanek and M. Yoshimura, "Processing and properties of hydroxyapatite-based biomaterials for use as hard tissue replacement implants," Journal of Materials Research, vol. 13, no. 1, pp. 94-117, 1998.

[7] T. J. Webster, R. W. Siegel, and R. Bizios, "Enhanced surface and mechanical properties of nanophase ceramics to achieve orthopaedic/dental implant efficacy," Key Engineering Materials, vol. 192-195, pp. 321-324, 2001.

[8] T. J. Webster, C. Ergun, R. H. Doremus, R. W. Siegel, and R. Bizios, "Enhanced functions of osteoblasts on nanophase ceramics," Biomaterials, vol. 21, no. 17, pp. 1803-1810, 2000.

[9] S. M. Zakaria, S. H. S. Zein, M. R. Othman, F. Yang, and J. A. Jansen, "Nanophase hydroxyapatite as a biomaterial in advanced hard tissue engineering: a review," Tissue Engineering Part B: Reviews, vol. 19, no. 5, pp. 431-441, 2013.

[10] H.-W. Kim, H.-E. Kim, and V. Salih, "Stimulation of osteoblast responses to biomimetic nanocomposites of gelatinhydroxyapatite for tissue engineering scaffolds," Biomaterials, vol. 26, no. 25, pp. 5221-5230, 2005.

[11] A. C. Tas, "Synthesis of biomimetic Ca-hydroxyapatite powders at $37^{\circ} \mathrm{C}$ in synthetic body fluids," Biomaterials, vol. 21, no. 14, pp. 1429-1438, 2000.

[12] F. de Paula do Desterro, M. W. Caminha, E. S. Gonçalves, G. M. Vidigal Junior, and M. B. Conz, "The interaction between implantology and materials science," Dental Press Implantology, vol. 7, no. 2, pp. 60-66, 2013.

[13] E. Karamian, A. Khandan, M. R. K. Motamedi, and H. Mirmohammadi, "Surface characteristics and bioactivity of a novel natural HA/zircon nanocomposite coated on dental implants," BioMed Research International, vol. 2014, Article ID 410627, 10 pages, 2014.

[14] T. Kokubo and H. Takadama, "Simulated body fluid (SBF) as a standard tool to test the bioactivity of implants," in Handbook of Biomineralization: Biological Aspects and Structure Formation, pp. 97-109, Wiley-VCH, 2008.
[15] A. Al-Haddad, M. G. Kutty, N. H. Abu Kasim, and Z. A. C. Che Ab Aziz, "Physicochemical properties of calcium phosphate based coating on gutta-percha root canal filling," International Journal of Polymer Science, vol. 2015, Article ID 414521, 5 pages, 2015.

[16] L. Jonášová, F. A. Müller, A. Helebrant, J. Strnad, and P. Greil, "Biomimetic apatite formation on chemically treated titanium," Biomaterials, vol. 25, no. 7-8, pp. 1187-1194, 2004.

[17] S. Lavenus, G. Louarn, and P. Layrolle, "Nanotechnology and dental implants," International Journal of Biomaterials, vol. 2010, Article ID 915327, 9 pages, 2010.

[18] J. E. Davies, "Understanding peri-implant endosseous healing," Journal of Dental Education, vol. 67, no. 8, pp. 932-949, 2003.

[19] B. R. Chrcanovic, A. R. Pedrosa, and M. D. Martins, "Chemical and topographic analysis of treated surfaces of five different commercial dental titanium implants," Materials Research, vol. 15, no. 3, pp. 372-382, 2012.

[20] C. C. Villar, G. Huynh-Ba, M. P. Cochran, and D. L. Cochran, "Wound healing around dental implants," Endodontic Topics, vol. 25, no. 1, pp. 44-62, 2011.

[21] T. Kokubo, H. Kushitani, S. Sakka, T. Kitsugi, and T. Yamamuro, "Solutions able to reproduce in vivo surface-structure changes in bioactive glass-ceramic A-W ${ }^{3}$," Journal of Biomedical Materials Research, vol. 24, no. 6, pp. 721-734, 1990.

[22] B. Kundu, A. Lemos, C. Soundrapandian et al., "Development of porous HAp and $\beta$-TCP scaffolds by starch consolidation with foaming method and drug-chitosan bilayered scaffold based drug delivery system," Journal of Materials Science: Materials in Medicine, vol. 21, no. 11, pp. 2955-2969, 2010.

[23] H. Zhou, J. G. Lawrence, A. H. Touny, and S. B. Bhaduri, "Biomimetic coating of bisphosphonate incorporated CDHA on Ti6Al4V," Journal of Materials Science: Materials in Medicine, vol. 23, no. 2, pp. 365-374, 2012.

[24] S. Jalota, S. B. Bhaduri, and A. C. Tas, "Effect of carbonate content and buffer type on calcium phosphate formation in SBF solutions," Journal of Materials Science: Materials in Medicine, vol. 17, no. 8, pp. 697-707, 2006.

[25] J. E. Davies, E. Ajami, R. Moineddin, and V. C. Mendes, “The roles of different scale ranges of surface implant topography on the stability of the bone/implant interface," Biomaterials, vol. 34, no. 14, pp. 3535-3546, 2013.

[26] A. Wennerberg and T. Albrektsson, "Effects of titanium surface topography on bone integration: a systematic review," Clinical Oral Implants Research, vol. 20, no. 4, pp. 172-184, 2009.

[27] F. Rupp, R. A. Gittens, L. Scheideler et al., "A review on the wettability of dental implant surfaces I: theoretical and experimental aspects," Acta Biomaterialia, vol. 10, no. 7, pp. 2894-2906, 2014.

[28] D. Buser, S. F. M. Janner, J.-G. Wittneben, U. Brägger, C. A. Ramseier, and G. E. Salvi, "10-year survival and success rates of 511 titanium implants with a sandblasted and acid-etched surface: a retrospective study in 303 partially edentulous patients," Clinical Implant Dentistry and Related Research, vol. 14, no. 6, pp. 839-851, 2012.

[29] S. K. Roehling, B. Meng, and D. L. Cochran, "Sandblasted and acid-etched implant surfaces with or without high surface free energy: experimental and clinical background," in Implant Surfaces and Their Biological and Clinical Impact, pp. 93-136, Springer, Berlin, Germany, 2015.

[30] P. Preshaw, "Summary of: implant surface characteristics and their effect on osseointegration," British Dental Journal, vol. 218, no. 5, pp. 292-293, 2015. 
[31] M. Kulkarni, A. Mazare, P. Schmuki, A. Iglič, and A. Seifalian, "Biomaterial surface modification of titanium and titanium alloys for medical applications," in Nanomedicine, pp. 111-136, One Central Press, Manchester, UK, 2014.

[32] S.-W. Lee, B.-D. Hahn, T. Y. Kang et al., "Hydroxyapatite and collagen combination-coated dental implants display better bone formation in the peri-implant area than the same combination plus bone morphogenetic protein-2-coated implants, hydroxyapatite only coated implants, and uncoated implants," Journal of Oral and Maxillofacial Surgery, vol. 72, no. 1, pp. 5360, 2014.

[33] M. G. Gandolfi, P. Taddei, F. Siboni et al., "Micro-topography and reactivity of implant surfaces: an in vitro study in simulated body fluid (SBF)," Microscopy and Microanalysis, vol. 21, no. 1, pp. 190-203, 2015.

[34] J. H. Sörensen, L. Dürselen, K. Welch et al., "Biomimetic hydroxyapatite coated titanium screws demonstrate rapid implant stabilization and safe removal in-vivo," Journal of Biomaterials and Nanobiotechnology, vol. 6, pp. 20-35, 2015.

[35] D. Oscar, B. Victor, Z. Jésica, and G. Romina, "Comparative in vitro study of surface treatment of grade II titanium biomedical implant," in VI Latin American Congress on Biomedical Engineering CLAIB 2014, Paraná, Argentina 29, 30 \& 31 October 2014, vol. 49 of IFMBE Proceedings, pp. 183-186, Springer, 2015.

[36] J. H. Lee, A. S. Madden, W. M. Kriven, and A. Cuneyt Tas, "Synthetic aragonite $\left(\mathrm{CaCO}_{3}\right)$ as a potential additive in calcium phosphate cements: evaluation in tris-free SBF at $37^{\circ} \mathrm{C}$," Journal of the American Ceramic Society, vol. 97, no. 10, pp. 3052-3061, 2014.

[37] A. C. Tas and S. B. Bhaduri, "Rapid coating of Ti6Al4V at room temperature with a calcium phosphate solution similar to $10 \mathrm{x}$ simulated body fluid," Journal of Materials Research, vol. 19, no. 9, pp. 2742-2749, 2004. 

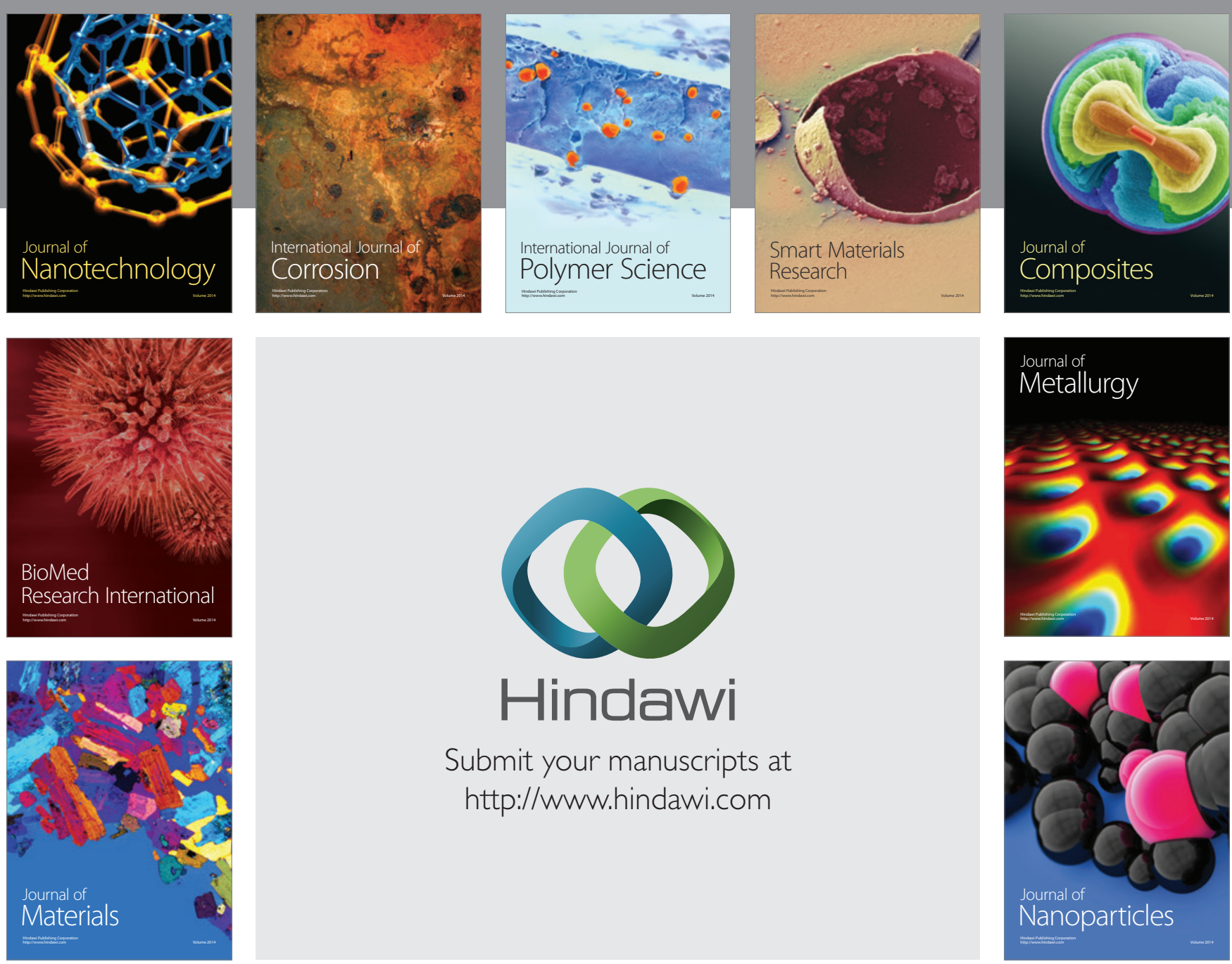

Submit your manuscripts at http://www.hindawi.com


\section{The Scientific World Journal}
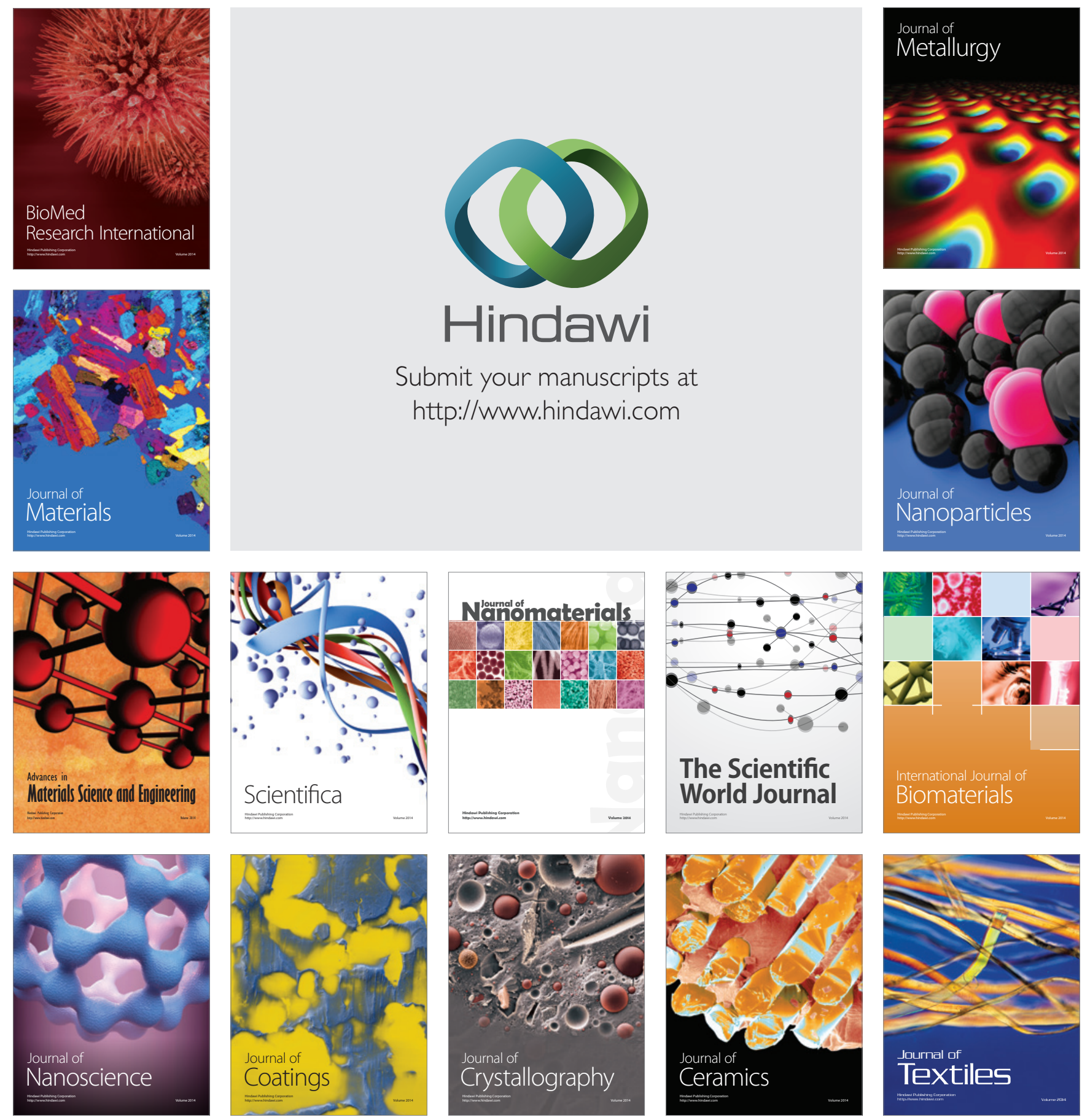